\title{
Influence Factor Analysis of Extracurricular Physical Exercise on Mental Health in College Student
}

\author{
Xianfu Wang \\ School of Physical Education, Zhengzhou Institute of Technology \\ tuke126@126.com \\ ${ }^{\star}$ Corresponding Author: Xianfu Wang
}

Keywords: College Students, Extracurricular Physical Exercise, Mental Health.

\begin{abstract}
This study investigated the application of Symptom Checklist (SCL-90) and the evaluation on extracurricular physical exercise on mental health in Henan college students, and the study on influence factor analysis. The first-hand information could improve the university physical education, and develop student's life-long physical awareness, capacity and habits, in order to promote the smooth implementation of the national fitness program to provide reference.
\end{abstract}

\section{Introduction}

The rapid development of modern society not only could enable people highly enjoy the wealth of material civilization, but also the spiritual civilization achievements. While, the fast pace of social life, frequent stress and intense competition also brought unprecedented mental pressure and social problems, such as mental disorder, psychological disease, nervous psychosis and social maladjustment [1]. These became the main factors influencing the modern health. And its harmfulness was rising rapidly [2]. Extracurricular physical exercise could strengthen students' physical fitness, promote students' psychological health, cultivate the good living habits, enhance organizational discipline, strengthen the construction of spiritual civilization and create a good study habit, conscientiously exercise habit, school spirit and benefit the students life-long health[3]. Therefore, how to make students participate in extracurricular physical exercise consciously and form lifelong physical exercise habits, so as to cope with the various challenges faces by the modern social life. This was an urgent requirement to solve the problem.

\section{Objects and method}

The research object of this study was the colleges and universities students (non-PE) in Henan area

\subsection{Sampling method}

Based on the size of the colleges and universities students population in Henan, this article selected 8 representative schools, which were Zhengzhou University, Henan University of Technology, Henan Agricultural University, North China University of Water Resources and Electric Power, Zhengzhou University of Light Industy, Henan Institute of Science and Technology, Henan University of Traditional Chinese Medicine, Henan University of Economics and Law. The randomly selected enrolled 1200 students were in $19 \sim 25$ years of age, and the average age was 20.6 \pm 1.18 years old. And all were freshman, sophomore, junior and senior.

\subsection{Research methods}

\subsubsection{Literature and material method}

More than 20 sports literatures were referred in this study. And the relevant 30 academic papers were browsed on China National Knowledge Infrastructure (www.cnki.net) and China Academic Network (ww.tiyujie.com) and other web sites. This provided a lot of theory, methods and basis for this study. 


\subsubsection{Expert interviews}

Physical theory expert interviews were performed to understand the influence factor analysis of extracurricular physical exercise on mental health in college students in Henan area.

\subsubsection{Mathematical statistics}

1130 valid questionnaires were selected through unified scoring standard process. The effective rate was $93.5 \%$. The measured data were input into computer. SPSS10.0 for Windows statistical software were adopted for processing the data.

\section{Results and analysis}

\subsection{Factor analysis on students' extracurricular physical exercise and mental health}

Through the investigation of college student's current condition on participating in physical exercise, the features of extracurricular physical exercise were achieved for the college enrolled students in Henan area. It provided strong scientific theoretical basis and guarantee for the following influence factors of extracurricular physical exercise on mental health [4, 5]. Influencing factors of extracurricular physical training on mental health were mainly from the overall level of mental health of college students and psychological differences crowd indicators on physical activity and the non-exercise of the crowd. It could promoted mental health exercise prescription, such as different sports, after-school sports exercise, exercise intensity degree. All these were to study the mechanism of extracurricular physical training to improve mental health and other factors in order to understand the mental health of college students in Henan area. It could better participate in extracurricular physical exercise services, thus promoted the development of sports in universities in Henan area.

\subsection{Current situation of college students psychological healthy level in Henan area}

Table 3-1 obtained through research, colleges students SCL-90 symptom factor higher than the national average of students, several symptoms of depression among the factors being tested factors, physical factors. There was a clear anxiety factor difference $(P<0.05)$, the symptoms of other factors had no significant difference $(P<0.05)$.In 1130 college students, 300 people had different degrees of psychological problems, $26.5 \%$ of the total number of students, which was further illustrated in northern regions of college students' mental health had a considerable number of university students had different degrees of problems, it required to participate extracurricular physical exercise to gradually improve their mental state, so as to form a good state of mind to finish college.

Table 3-1. South central agricultural colleges and universities students SCL-90 factor compared to the national average of college students

\begin{tabular}{|c|c|c|c|c|c|c|}
\hline \multirow{2}{*}{$\begin{array}{c}\text { SCL-90 } \\
\text { classification }\end{array}$} & \multicolumn{2}{|c|}{$\begin{array}{c}\text { college students in } \\
\text { Henan area }(\mathrm{n}=1130)\end{array}$} & \multicolumn{2}{c|}{$\begin{array}{c}\text { College studetns indomestic } \\
\text { area (n=1068) }\end{array}$} & \multirow{2}{*}{$t$} & $P$ \\
\cline { 2 - 6 } & $x$ & $S$ & $x$ & $S$ & & \\
\hline Forcing factor & 1.71 & 0.49 & 1.56 & 0.47 & 0.026 & $<0.05$ \\
\hline Anxiety factor & 1.57 & 0.55 & 1.53 & 0.51 & 0.052 & $<0.05$ \\
\hline Phobic factor & 1.73 & 0.67 & 1.70 & 0.52 & 0.047 & $<0.05$ \\
\hline $\begin{array}{c}\text { Interpersonal } \\
\text { sensitivity factor }\end{array}$ & 1.63 & 0.55 & 1.51 & 0.58 & 0.038 & $<0.05$ \\
\hline Paranoid factor & 1.59 & 0.56 & 1.35 & 0.44 & 0.044 & $<0.05$ \\
\hline Depression factor & 1.46 & 0.62 & 1.39 & 0.56 & 0.036 & $<0.05$ \\
\hline $\begin{array}{c}\text { Somatization } \\
\text { factor }\end{array}$ & 1.25 & 0.34 & 1.24 & 0.43 & 0.066 & $<0.05$ \\
\hline Hostility factor & 1.42 & 0.58 & 1.38 & 0.50 & 0.053 & $<0.05$ \\
\hline Psychotic factor & 1.34 & 0.43 & 1.32 & 0.43 & 0.083 & $<0.05$ \\
\hline
\end{tabular}

\subsection{Analysis on general level of psychology health for students in Henan area}

It could conclude from the survey, the SCL-90 aggregate score and active detection rate running between 3.73\% 27.26\% in the researched students of universities in Henan area. As the symptom factor with the number of people who get two score, the rant just as the following: forcing agents, 
anxiety factor, phobic, interpersonal sensitivity factor, paranoid ideation, depression factor, somatization, hostility factor and psychotic factor. In some degree or in one point psychology problems in the crowd of students of agricultural university in the center of south region, which should arise the attention of PH department. Nowadays, it made a slight sense that almost every higher academies advocate the quality education and health education and built all kids of psychology counseling center for many related reasons. And this reveals some awaiting to solve problems such as whether the local government do according to the higher government? How much did the university PH department invest? And so on. Therefore, the core problem was to find a practical and effective way to improve the common level of the psychology healthy problem for the college students.

Table 3-2. Unified standard table of college enrolled students psychological health level in Henan area $(n=1130)$

\begin{tabular}{|c|c|c|c|c|}
\hline SCL-90 classification & $x$ & $S$ & $\begin{array}{c}\text { Overall 160 scores, } \\
\text { factor was 2 points }\end{array}$ & accounting for \\
\hline Overall & 136.15 & 35.11 & 217 & $19.20 \%$ \\
\hline Forcing factor & 1.34 & 0.27 & 47 & $3.73 \%$ \\
\hline Anxiety factor & 1.56 & 0.58 & 160 & $14.16 \%$ \\
\hline Phobic factor & 1.54 & 0.47 & 176 & $15.84 \%$ \\
\hline Interpersonal sensitivity factor & 1.57 & 0.57 & 178 & $15.26 \%$ \\
\hline Paranoid factor & 1.49 & 0.49 & 157 & $27.26 \%$ \\
\hline Depression factor & 1.78 & 0.52 & 312 & $4.25 \%$ \\
\hline Somatization factor & 1.31 & 0.38 & 48 & $15.66 \%$ \\
\hline Hostility factor & 1.51 & 0.56 & 177 & $14.96 \%$ \\
\hline Psychotic factor & 1.59 & 0.43 & 169 & \\
\hline
\end{tabular}

3.4 The difference psychology objects between with physical training and without training for university students in Henan area

It can perfect the central never system, improve the harmonization effective of the delight and restrain of the cerebrum skin, enhance the process of alternative delight and restrain by taking $\mathrm{PH}$ exercises after class [6]. Thereby improving balance and accuracy of cerebral cortical neurons, and promote the development of human perception, thinking to imagine the brain flexibility, coordination, speed of response can be improved and enhanced; perception keen, flexible thinking, rich imagination. Much of this could ease and improve the part of people's consciousness and memory fuzzy, hazy, obstacles intellectual delusions and hallucinations appear. Students of modern mental health factors are the most important flag physical activity, physical activity often cannot only greatly improve the emotional state of college students, and college students to be able to bring some of euphoria and well-being directly, while different time college students reduce tension and anxiety, so as to regulate Students emotional state, improve mental health of college students. 
Table 3-3. Psychological index standard table for extracurricular physical exercise population and nonphysical exercise population

\begin{tabular}{|c|c|c|c|c|c|c|c|c|}
\hline \multirow{2}{*}{$\begin{array}{l}\text { SCL-90 } \\
\text { classification }\end{array}$} & \multicolumn{3}{|c|}{$\begin{array}{c}\text { extracurricular physical } \\
\text { exercise population }(n=517)\end{array}$} & \multicolumn{3}{|c|}{$\begin{array}{l}\text { nonphysical exercise } \\
\text { population }(n=613)\end{array}$} & \multirow[t]{2}{*}{$t$} & \multirow[t]{2}{*}{$P$} \\
\hline & $x$ & $S$ & Positive & $x$ & $S$ & Positive & & \\
\hline Overall & 122.72 & 7.94 & $14.07 \%$ & 141.43 & 34.49 & $24.67 \%$ & 2.563* & 0.015 \\
\hline Forcing factor & 1.31 & 0.38 & 0.00 & 1.43 & 0.45 & $8.53 \%$ & 1.005 & 0.317 \\
\hline Anxiety factor & 1.46 & 0.25 & $17.97 \%$ & 1.71 & 0.37 & $23.34 \%$ & 3.063* & 0.005 \\
\hline Phobic factor & 1.56 & 0.29 & $8.16 \%$ & 1.57 & 0.65 & $32.57 \%$ & 1.612 & 0.128 \\
\hline $\begin{array}{c}\text { Interpersonal } \\
\text { sensitivity } \\
\text { factor } \\
\end{array}$ & 1.28 & 0.41 & $14.12 \%$ & 1.65 & 0.47 & $18.21 \%$ & 1.586 & 0.089 \\
\hline $\begin{array}{l}\text { Paranoid } \\
\text { factor }\end{array}$ & 1.30 & 0.29 & $8.07 \%$ & 1.47 & 0.38 & $20.27 \%$ & $2.897 *$ & 0.004 \\
\hline $\begin{array}{l}\text { Depression } \\
\text { factor }\end{array}$ & 1.37 & 0.40 & $1.94 \%$ & 1.71 & 0.64 & $18.55 \%$ & $2.713^{*}$ & 0.007 \\
\hline $\begin{array}{c}\text { Somatization } \\
\text { factor }\end{array}$ & 1.27 & 0.39 & 0.00 & 1.46 & 0.31 & $8.53 \%$ & 1.695 & 0.078 \\
\hline $\begin{array}{l}\text { Hostility } \\
\text { factor }\end{array}$ & 1.37 & 0.47 & $11.02 \%$ & 1.48 & 0.58 & $17.37 \%$ & 1.901 & 0.088 \\
\hline $\begin{array}{l}\text { Psychotic } \\
\text { factor }\end{array}$ & 1.41 & 0.36 & $2.58 \%$ & 1.73 & 0.43 & $19.50 \%$ & 1.611 & 0.124 \\
\hline $\begin{array}{c}\text { Emotional } \\
\text { stability factor }\end{array}$ & 18.53 & 23.12 & 0.00 & 22.20 & 7.17 & 0.00 & 1.821 & 0.085 \\
\hline
\end{tabular}

Note: $* P<0.05$.

A large number of scientific studies show that exercise can effectively adjust the tension, relieve psychological stress, depression and improve mood, reduce the degree of depression. From one source of stress, after-school physical activity may have a direct effect physiological, psychological decompensation. This effect may encourage students in a more rational to look at life encountered. But then becomes an important addition, after-school sports training colleges and universities are always carried out in a certain social environment, extracurricular physical exercise always crowd (college students) undergoing direct or indirect contacts and exchanges, Higher college students in extracurricular participation in physical training can gradually forget about those worries and pain, overcome withdrawn, expand exchanges themselves and society, and coordinate relationships, improve social adaptability. Frequency of survey results college physical activity derive, participation average score curricular sports activities of the population nine symptoms were lower than non-factor on Physical Activity crowd. After scientific statistical test showed physical activity crowd (college students) and people involved in non-curricular sports activities (college students) forcing factor, anxiety factor, there is a significant difference in average score hostility factor. From out of the display, the Physical Activity crowd total score of 122.72, not much better than on Physical Activity crowd (college students) total score 141.43, statistical test results obtained there are significant differences. Physical Activity crowd (college students) in the total score, depression factor, interpersonal sensitivity factor, anxiety factor, factor hostility, phobic, paranoid, psychotic factor positive rate was significantly lower than the school does not participate in physical exercise crowd (college students).

Lesson crowd participation in physical exercise (Students) factor index in psychiatric symptoms and emotional stability factor is not much better than on physical activity crowd (college students), but there was no significant difference. Thus, participation in extracurricular physical exercise could really improve and enhance the mental health of college students in Henan colleges and universities. 


\section{Conclusion}

\subsection{College students' mental health problem detection rate and difference in Henan colleges and universities}

The overall level was slightly below the national college students, college students had higher detection rate of mental health problems. Wherein the body, depression, anxiety and other factors showed significant differences in male and female students of hostility, paranoia, interpersonal relationships and other factors showed significant differences. In the survey of 1130 college students, 300 people had varying degrees of mental health problems, accounting for $26.5 \%$ of the total number of college students surveyed [7]. The statistics detected on physical activity students show great gender differences, grade differences, professional differences. College students in northern regions of SCL-90 total score and positive factor in the detection rate of between 3.89\% 27.26\%, many of the symptoms of the positive rate of more than $10 \%$, a little explanation into Henanl colleges and universities considerable. There were different degrees or mental health of a number of aspects of college students.

\subsection{Strength of the participation in extracurricular physical exercise}

Physical activity could improve and enhance the mental health of college students, the findings obtained to participate in strength curricular sports activities of different differences, Physical activity groups and non-physical activity population mental health level. There were significant difference. Students load intensity Henan colleges and universities on physical activity was based on mental health effects of moderate-intensity-based, after-school sports participation in moderate intensity exercise produced superior physical activity intensity and high-intensity small. A physical exercise so nervous, confusion, fatigue, anxiety, depression and anger and other negative emotional state improved significantly to energy feeling and a pleasant degree of improved significantly; participation curricular sports activities of mixed and non-periodic physical exercises population regulation rate good mental health and emotional state people did not participate in extracurricular physical exercise, particularly intense confrontational school physical education programs (such as basketball, football matches, etc.) the effect was more prominent. However, there were differing views, confrontational intense exercise program of after-school sports (such as basketball, football matches, etc.), and higher probability of failure, defeat, the state of mind of many individuals (such as: happiness, perceived competence, achievement a sense of pride, etc.) had different degrees of impact, with the attendant could spoil actively participate in extracurricular physical exercise heat. School physical education programs in different item groups on the mental health effects of the absence of significant differences, terms of participation extracurricular intensity physical activity, the results show, after-school physical activity of boys in moderate intensity, the girls in the small intensity extracurricular physical training and sports physical attitude feel exercise can produce a more positive impact.

Physical activity population in the total score were significantly lower than the average physical activity groups $(P<0.05)$, the positive rate of symptoms was significantly lower than non-participating class Exercisers $(P<0.05$ ), which confirmed into a physical activity was one of the effective means to improve and enhance the students' psychological health.

\section{References}

[1] QingJian Ding, Fang Fan. Study in the effect of sports in treating the psychology problem for college students. Journal of Beijing Sports University. Vol. 25, No. 4, p. 468-470. (2002)

[2] Zuosong Chen, Hong Chen. The study situation and development trend for international sports psychology. Journal of Chengdu Physical Education Institute. Vol. 28, No. 3, P. 80-84. (2002)

[3] Jianxiong Yang, Liqi Yang. Comparison study between the crowd of higher physical exercise 
students and none taking students. Journal of Beijing Sports University. Vol. 26, No. 5, p. 613-614. (2003)

[4] Zheng yu Tang. Summarize of the study about the relationship between exercise and low depressed. Physical Scientific Research. No. 3, p. 46-47. (2000)

[5] Hausenblas, HA, Brewer, B W,Van Raalte J L. Self-presentation and exercise[. Journal of Applied Sport Psychology. No.16, p. 3-18. (2004)

[6] Zu Chen. Student's physical health and social adaption. Beijing: international culture publishing company and educational scientific press. (2002)

[7] Xia Xu. .Study on the relationship between the measures for social anxious character and physical exercise. East China North University. (2003) 